\title{
DOENÇA E MORTE NAS NARRATIVAS VISIONÁRIAS DO ALÉM MEDIEVAL
}

\author{
Disease and Death in Visionary Narratives of Medieval \\ Beyond
}

\author{
Prof. ${ }^{a}$ Dr. ${ }^{a}$ Solange Pereira Oliveira (IFMA/BRATHAIR) \\ Docente de História do Instituto Federal do Maranhão \\ E-mail: solstar22@hotmail.com \\ ORCID: https://orcid.org/0000-0001-5071-4130
}

Recebido em: 12/10/2020

Aprovado em: 15/12/2020

\begin{abstract}
Resumo: O objetivo deste texto é apresentar algumas considerações iniciais sobre as funções das doenças nas narrativas visionárias do Além Medieval. Estas são mencionadas em um vasto corpus de relatos que mencionam a experiência da viagem da alma de personagens, em um estado de quase morte, ao mundo do Além. As menções aos diferentes tipos de enfermidades as quais são acometidos os viajantes mostra uma intrínseca relação sobre as circunstâncias para a partida temporária ao mundo dos mortos. É ao curso de uma enfermidade que se dará o início da entrada no Além. Pretende-se, portanto, tecer considerações sobre as relações entre doenças e a experiências de quase morte nas estruturas das narrativas visionárias do Além Medieval.
\end{abstract}

Palavras-chave: Doença. Morte. Narrativas visionárias medievais.

Abstract: The purpose of this text is to present some initial considerations about the functions of diseases in the visionary narratives of the Medieval Beyond. These are mentioned in a vast corpus of reports that mention the experience of the journey of the soul of characters, in a state of near death, to the world of the Hereafter. The mention of the different types of illnesses that travelers experience shows an intrinsic relationship about the circumstances for the temporary departure to the world of the dead. It is in the course of an illness that entry into the Hereafter will begin. It is intended, therefore, to make considerations about the relationship between diseases and the experience of near death in the structures of the visionary narratives of the Medieval Beyond.

Keywords: Disease. Death. Medieval visionary narratives. 


\section{Introdução}

É fato que as doenças produzem uma historicidade revelada através das diversas temporalidades e espaços. Como menciona Jacques Le Goff, a doença pertence à História, uma história que não está ligada apenas aos progressos científicos e tecnológicos, mas também aos saberes e práticas ligadas às estruturas sociais, mentais, as representações e dentre outras modalidades (Le Goff, 1985, p.7-8).

Quando se trata de doenças na Idade Média seus sentidos não podem ser dissociados dos conjuntos de crenças que acomete tanto o corpo quanto a alma. É quase sempre um elemento que visa externar simbolicamente através do corpo a parte visível de uma alma doente de pecados. Isto porque na sociedade medieval, eminentemente cristã, não havia a dissociação entre o corpo e a alma, até o momento da morte, quando ocorre a separação de ambos. Dessa forma, "concebia-se a relação entre a alma e o corpo de uma maneira tão estreita e imbricada que a doença era uma entidade psicossomática” (LE GOFF, 2006, p.108).

$\mathrm{Na}$ sociedade medieval várias enfermidades que acometem o corpo são vistas como a doença da alma ou manifestações visíveis dos pecados as quais estão associadas a um sentido simbólico espiritual, isto é, inserida em um discurso religioso cristão. Como exemplo, a lepra foi alvo desse contexto de associação moral e teológico, pois se compreendia como um produto do pecado sexual que se manifestava em razão dos maus comportamentos cristãos. Da mesma maneira, lancemos um último exemplo a essa questão, o caso da epidemia da peste negra, que não deixou de estar inserida em um discurso religioso enquanto compreensão de uma suposta ira divina em razão dos pecados cometidos pela humanidade.

Vista sob a ótica religiosa, a peste foi compreendida como um sinal da cólera de Deus que, em razão dos pecados dos homens e mulheres, punia a todos de forma coletiva. Com essa interpretação, os fiéis recorriam às penitências, aos cultos e às devoções para tentar apaziguar a ira divina e salvar as próprias almas.

É evidente que nem todas as doenças na Idade Média estavam associadas a uma questão de pecado, as manifestações destas também devem ser compreendidas por outro viés. Neste caso, a doença que atinge o corpo pode ser tanto um sinal simbólico de consequências de desvios cristãos quanto um sinal de eleição, pois funcionam como 
provações nesta vida que podem levar a um futuro na glória do Paraíso. Segundo Jean Claude-Schmitt:

Qualquer que seja a origem, a doença é um signo ambíguo: signo do pecado, ela aparece como um justo castigo, mesmo sendo uma incitação positiva à conversão individual ou coletiva, nos casos das epidemias. Mas é também signo da virtude, até mesmo do amor de Deus, quando sua função é colocar em provação o cristão e, sobretudo, o santo. (SCHMITT, 2018, p. 289)

Voltemos ao exemplo da lepra na Idade média, onde a própria Igreja ensinava que estes deveriam despertar à compaixão, pois "divulgava a ideia que os leprosos eram, em certo sentidos, particularmente favorecidos por Deus, por que permitia que sofresse nesta vida, como Cristo havia sofrido". (RICHARDS, 1993, p.160). Da mesma forma, era preciso prestar assistência aos leprosos, apesar do medo e da repulsa que a doença causava nos medievos, como forma de praticar a caridade, presente em diverso corpus hagiográficos que trazem histórias de santos cuidando das pessoas acometidas pela doença.

Lembremos-nos dos ensinamentos no Evangelho de Lucas (LC 16, 19-31) que conta a história do pobre Lázaro que morre acometido das chagas de úlceras após seu corpo sofrer neste plano para que depois a sua alma fosse acolhida por Abrãao. Aliás, vários hospitais destinados aos leprosos, administradas pela Igreja durante a Idade, eram dedicados a são Lázaro.

Estas são as tensões simbólicas de um doente na Idade Média que se apresenta com um duplo significado nos discursos cristãos, traduzidos muitas vezes em uma relação de ambiguidade entre a virtude e o pecado. Quando se trata da doença na Idade Média, qualquer que seja a origem da enfermidade ela estará sempre associada a um justo castigo ou a uma provação cristã. Como escreve Mário Jorge da Motta Bastos:

A doença é um locus de reflexão e produção de discursos que nela se originam, mas que a ultrapassam. Sob a ótica cristã, fomentou a abordagem do pecado, da culpa, do arrependimento e da redenção, do papel social da caridade e, em extremo, da fundamental observância das leis que regulamentam o pacto entre Deus e os homens. (BASTOS, 2009, p.48) 
As doenças também estiveram relacionadas às experiências de viajantes do Além nas narrativas visionárias medievais que foram amplamente difundidas ao longo da Idade Média, com destaque para o século XII onde se observa uma rica produção de relatos de visão. Os mosteiros foram os principais centros de produção e divulgação desse tipo de literatura que informa sobre as experiências de viajantes do Além que empreenderam uma jornada às regiões onde residem os mortos: o Inferno, Purgatório e Paraíso.

Os testemunhos dos viajantes nas narrativas do Além se davam principalmente sobre a forma de visão ou visio, expressão latina que abrange uma multiplicidade de sentidos nos diverso corpus textuais na Idade Média, principalmente relacionada a três diferentes modalidades: sonhos, visões dos místicos e viagens extáticas. Deteremos-nos nesta última também conhecida como viagem da alma ao Além onde ocorre um processo bastante dinâmico, tal como o êxtase, isto é, a separação da alma do corpo. ${ }^{1}$

Destacamos aqui alguns elementos que constituem a estrutura da narrativa no século XII, cujo esquema remete aos séculos precedentes, no caso, a partir do século VII que apresenta um esquema bem peculiar sobre as Visões do Além. As principais características são: 1) O protagonista viajante apresenta um estado de quase morte, isto, é, fica aparentemente morto; 2) A separação da alma do corpo; 3) A viagem da alma ao Além, seguindo um itinerário aos lugares onde habitam os mortos sob a condução de um guia; 4) $\mathrm{O}$ protagonista testemunha as características do Além e, às vezes, o próprio tem a necessidade de expiar os seus pecados; 5) O retorno da alma ao corpo.

Considerando a estrutura citada, tanto mencionada por diversos estudiosos da temática, podemos acrescentar nesta mais uma característica de relevante importância para o início da experiência de quase morte do viajante, a doença. Isso se faz necessário devido a um número bastante expressivo de narrativas visionárias do Além que mencionam em suas estruturas o estado patológico do protagonista como o processo iniciador da sua experiência no além-túmulo. Geralmente a custo de uma doença que se inicia a separação física e espacial, ou seja, entre o corpo e a alma, o aqui e o Além.

Desse modo, o texto aqui apresentado pretende levantar considerações da importância da menção de algumas doenças nos relatos de viagens ao Além Medieval. Atentado para a sua funcionalidade na estrutura da narrativa e a sua relação com a experiência de quase morte dos protagonistas das almas viajantes. Outra questão a ser 
abordada se refere à natureza das doenças, a fim de identificarmos quais enfermidades estão relacionadas aos corpus textuais das narrativas visionárias medievais. Para esse estudo foram selecionados exemplos de fontes narrativas de viagem ao Além Medieval que abordam estas questões.

\section{Doenças e morte na estrutura das narrativas visionárias do além medieval}

Os relatos de viagens visionárias ao Além são um dos principais exemplos de narrativas onde os medievos conheciam as experiências de viajantes que cumpriam um caminho no além-túmulo para a purificação da alma ou do corpo como forma de obter a salvação. Desde os primeiros séculos do cristianismo já existia a crença de viajantes ao Além que realizavam um itinerário, com ou sem o corpo, "oferecida a pessoas excepcionais, por certo, mas destinada a voltar em seguida, mesmo por pouco tempo a vida terrestre habitual, confirmada por autoridades numerosas e diversa - Hermas, Tertuliano, Lactânio, Santo Agostinho [...]”. (DELUMEAU, 2003, p.72).

É a partir do século VII que encontramos nos textos de viagens ao Além as ações preliminares dos visionários antes da sua jornada ao mundo dos mortos, com mais detalhe a partir do século XII se estendendo até o século XV quando se revela de forma mais estruturada as circunstâncias pelas quais foram iniciadas as partidas para o Além. Seu estudo permite apreender a relação do estado corporal do protagonista visionário e o deslocamento da alma para onde habitam os mortos.

Neste aspecto a doença aparece, na maioria dos casos, como um elemento fundamental para se compreender como se inicia a jornada do viajante medieval para o além-túmulo, ou de outra forma, qual ação evidencia o momento em que a alma é separada do corpo antes da jornada aos lugares do Inferno, Purgatório e Paraíso. Geralmente, a narrativa se inicia com a apresentação do protagonista em seu estado corporal acometido por uma enfermidade caracterizando o fenômeno que dará início a partida da alma para uma viagem no pós-morte. Aliás, esta uma das peculiaridades típicas que podemos encontrar na estrutura desse gênero literário que condiciona ao viajante do Além ao processo de separação da alma da sua habitação temporária, o corpo, antes de começar a sua experiência no Além. 
Assim, o estado patológico do visionário lhe dará a condição necessária para a alma se dirigir para o mundo dos mortos enquanto o seu corpo fica em um estado inerte, isto é, desprovido da presença de movimento que indiquem sinais de vida corporal. Estrutura também característico que se impõem nos relatos visionários medievais que "contam como almas, provisoriamente separadas do corpo no decorrer de uma doença ou durante um momento de morte aparente, atravessam o mundo dos defuntos, terminando por trazer um testemunho para os vivos". (BASCHET, 2007, p. 381).

Essa questão nos permite fazer uma inferência ainda mais ampla sobre as implicações simbólica da doença que acomete o protagonista com a sua experiência de quase morte nos lugares que habitam as almas. Uma vez que fica evidente a relação entre um sintoma patológico sentido pelo viajante com o início do processo da separação da alma do corpo. Mas, também, as fronteira espaciais, ou seja, o deslocamento deste plano para o post-mortem, sobretudo para a saída da vida e entrada na morte.

Desse modo, os textos visionários mostram que o vínculo entre a alma e o corpo são desfeitas antes do viajante partir para o próximo mundo. Essa ação é realizada por um período simbólico temporário que vária em diversas narrativas, geralmente se dar em um tempo de três dias ou pode ser uma noite quando a alma do viajante fica em um estado de quase morte. Observa-se que essas durações são calculadas segundo o tempo terrestre, pois o tempo do Além não é medido como neste mundo. A esta temporalidade segue a mesma duração para que haja o retorno da alma para o corpo, que se encontra momentaneamente sem vida.

Como o protagonista, neste caso o visionário, está esvaziado da sua alma é considerado morto até o momento da passagem daquele tempo simbólico para retornar a reanimar o seu corpo sem vida. Praticamente em todos os textos do gênero de viagens ao Além apresentam esse esquema narrativo que coloca a doença como uma circunstância que impõem o protagonista a um estado aparente de morte. Existe, assim, a correlação da morte temporária do visionário com o motivo tópico da doença.

Desde "a Alta Idade Média, numerosos relatos de visões, sonhos e viagem ao além fazem menção à situação de transição entre a alma e o corpo, a alma viajando enquanto o corpo permanece inerte, como se estivesse morto." (SCHMITT, 20007, p.307). No caso específico dos relatos visionários os redatores deixam bem claro na 
estrutura narrativa que o protagonista está submetido apenas a uma morte temporária e não definitiva ao identificar no corpo doente alguns sinais de vida, o que atesta somente uma separação entre a alma e o corpo de forma temporária. A maneira de explicar essa questão para o leitor/receptor de que não houve uma passagem definitiva para o mundo dos mortos é revelar os elementos sintomáticos de vida corporal enquanto a alma viaja.

Segundo constata Claude Carozzi, certos redatores se esforçam em enumerar os sinais de vida que continua visível sobre o corpo. O mais frequente é um leve sopro perceptível pelas narinas ou sentindo o peito, certo calor ou a coloração avermelhada do rosto do visionário, sinais que o autor classifica como fenômenos que são raramente explicados nos textos. (CAROZZI, 1994, 571). Se há uma preocupação em revelar que o viajante visionário não fez sua passagem definitiva para o além-túmulo e apenas adoece de morte, por outro lado os redatores não deixaram de apresentar os sinais que atestam de forma temporária a morte do protagonista insistindo paralelamente entre os sinais de vida e os sinais da morte. Assim, são enumerados dentre outros sinais indicando o estado do viajante de semivivo ou quase morto, tais como a rigidez e a temperatura fria do corpo seguido de alguns movimentos corporais.

Dessa forma, percebe-se a preocupação das narrativas visionárias do Além em lançar as provas que certificam que o protagonista não realizou a passagem definitiva, ao utilizar aqueles recursos atestando a presença dos sinais de vida sem deixar é claro de evidenciar os elementos que também o leva a experiência sintomática da morte. Embora essa questão pareça ambígua, se interpretarmos através do nosso presente, para a época medieval faz todo sentido, pois havia a crença na viagem da alma de indivíduos, escolhidos por Deus, ao Além que retornaram à vida para contar a sua jornada no Outro Mundo.

Retomando a questão da doença, esta desempenha um papel-chave na experiência de quase morte do visionário ao qual nos permite elucidar a relação entre um sintoma patológico e a forma como aquele deixa esse mundo enquanto a sua alma é introduzida no espaço do Além. É claro que para além das doenças, existem outras maneiras de se dar início à entrada no Outro Mundo nos relatos de viagens visionárias medievais, principalmente quando se trata das vias de acesso espacial, no entanto, aqui me refiro às manifestações ou sintomas físicos que levam o protagonista a porta da morte. 
Dependendo das modalidades particulares de cada época em que se situa a narrativa há referências que indicam outras formas de entrada no Além. Para ficarmos em alguns exemplos citemos o sonho, sob a forma de visão, como elemento iniciador da viagem ao Além, sendo que às vezes este aparece atrelado à questão da doença. "O sonho tornou-se nos séculos XII e XIII uma "experiência total" que envolve o corpo e a alma, o indivíduo, suas relações com a coletividade dos cristãos e suas chances de salvação". (LE GOFF, 2002, p.525).

Neste sentido, ressalvado a referência de outros meios, sem nenhuma dúvida os redatores privilegiam o sintoma de uma doença como o elemento principal de condução do visionário, a um estado de quase morte, ao mundo do Além. ${ }^{2}$ Apesar de que para os próprios redatores esse fenômeno da partida da alma não é tão óbvio. A maioria deles descreve de forma diferente a natureza da doença que nem sempre é detalhada ou até mesmo identificada, contudo associam esta a uma aparência de morte. De qualquer forma, a doença juntamente com o êxtase são os principais fenômenos da partida da alma para a viagem ao Além. Segundo Carozzi, "alguns autores usam o sonho como mediador entre ambos, outros já transformam a viagem em sonho". (CAROZZI, 1994, $568)$.

Embora não seja o objetivo deste texto discutir as narrativas hagiógrafas neste contexto, não podemos deixar de mencionar como mais um exemplo de corpus documental importante para o estudo da função da doença em relatos visionários, pois é um elemento tópico que está presente em muitas produções de Victae Sanctorum. Frequentemente estas narrativas mencionam a enfermidade que acomete o protagonista durante os últimos dias de sua vida. No entanto, as doenças nas estruturas desses textos adquirem um estatuto de interpretação que difere das experiências dos viajantes do Além.

A enfermidade neste caso é uma espécie de sinal que convida o santo a se preparar para a morte, onde em seus últimos dias opera certos exercícios espirituais tais como a prática das virtudes, formas de aceses, orações e outros, como uma preparação para o trespasse. Para além disso, a doença dos santos tem uma particularidade em relação à doença do visionário, uma vez que ambas apresentam um papel oposto. Conforme explica Mattias Cavagna: 
[...] a doença é um topos que também caracteriza uma série de vitae sanctorum. Muitas vezes, os relatos hagiográficos insistem na doença que atinge o protagonista nos últimos dias de sua vida. A enfermidade, neste caso, é uma espécie de sinal que convida o santo a se preparar para a morte. Durante seus últimos dias, ele adota uma série de comportamento piedoso: intensifica as orações, as leituras, a recepção dos sacramentos. Ele está constantemente cercado por seus irmãos e seus fiéis, aos quais transmite os últimos ensinamentos e as últimas bênçãos. O santo suporta estoicamente a doença; seu sofrimento representa a última de suas penitências, permite que ele seja assimilado a um mártir (CAVAGNA, 2004, p. 40).

Ainda o autor, explica que nos relatos hagiográficos a doença é precursora de um evento, isto é, da morte do santo caracterizada como um acontecimento público dando lugar a uma organização de um cerimonial bem codificado. De modo contrário, a doença dos visionários provoca o isolamento, enfim, um evento secreto e misterioso. $\mathrm{O}$ arrebatamento extático do visionário aparece como um evento secreto e misterioso, enquanto a morte do santo sempre tem o caráter de uma cerimônia pública e solene (CAVAGNA, 2004, p. 40).

De fato, a escolha de uma doença como forma de eleição obriga o visionário a se isolar como uma condição essencial para a concretização do êxtase, ou seja, a separação da alma do corpo. Como explica Claude Carozzi, a função da doença é, portanto, trazer o visionário para um estado de morte presumida na medida em que o fator patológico "permite evidenciar melhor o momento em que o corpo chega ao ponto de morrer, sem ir para o outro lado". (CAROZZI, 1994, p. 576). Por outro lado, a evocação da doença do viajante também tem um papel significativo para a separação da dimensão da materialidade, pois aparece com função específica de ser o fator condicionante para a transição entre dois espaços: dos vivos e dos mortos.

\section{A natureza das doenças nos relatos visionários do além medieval}

Após a abordagem da função da doença nas estruturas das narrativas visionárias do Além, finalmente nos deteremos na identificação da sua natureza, ou seja, quais tipos de enfermidades são acometidos os visionários que o conduz a uma morte temporária, enquanto sua alma viaja ao Além. Para essa questão utilizaremos de uma seleção de corpus documentais que constituem exemplos de relatos sobre o Além para conhecermos quais doenças os redatores elegem nestas narrativas como fenômenos do processo de separação da alma do corpo. 
Como já mencionamos aqui, nem sempre a tipologia da doença é revelada nas estruturas dos relatos visionários indicando a circunstância em que o protagonista inicia a sua jornada no além-túmulo e, tão pouco, a sua descrição ou evolução no corpo. Em um bom número de narrativas, o redator simplesmente cita que o personagem viajante está doente, em seguida descreve as ações das experiências vividas por ele no mundo dos mortos e a volta da alma ao corpo. ${ }^{3}$

Dessa forma nem todos os textos visionários apresentam as manifestações ou identificação das doenças da mesma forma, pois em muitos casos a preocupação é sinalizar que o protagonista se encontra em um estado patológico sem que seja esclarecida qual a sua natureza ou até mesmo a sua progressão. Para ficarmos em um exemplo, a Visão do monge de Wenlock é um dos vários relatos que não precisa o tipo de patologia, menciona apenas que uma brutal doença havia despojado o visionário do seu corpo, sem identificar qual tipo de enfermidade lhe havia acometido originando, por assim dizer, o início da sua viagem no Além. ${ }^{4}$

Dito isso, o que deve reter a nossa atenção nesse momento é a identificação de quais doenças do corpo eram acometidos os visionários nas narrativas de viagens ao Além. Para essa questão, destacamos no esquema 1, os principais tipos de doenças que são mencionadas e acometem os protagonistas e consequentemente a partida da sua alma.

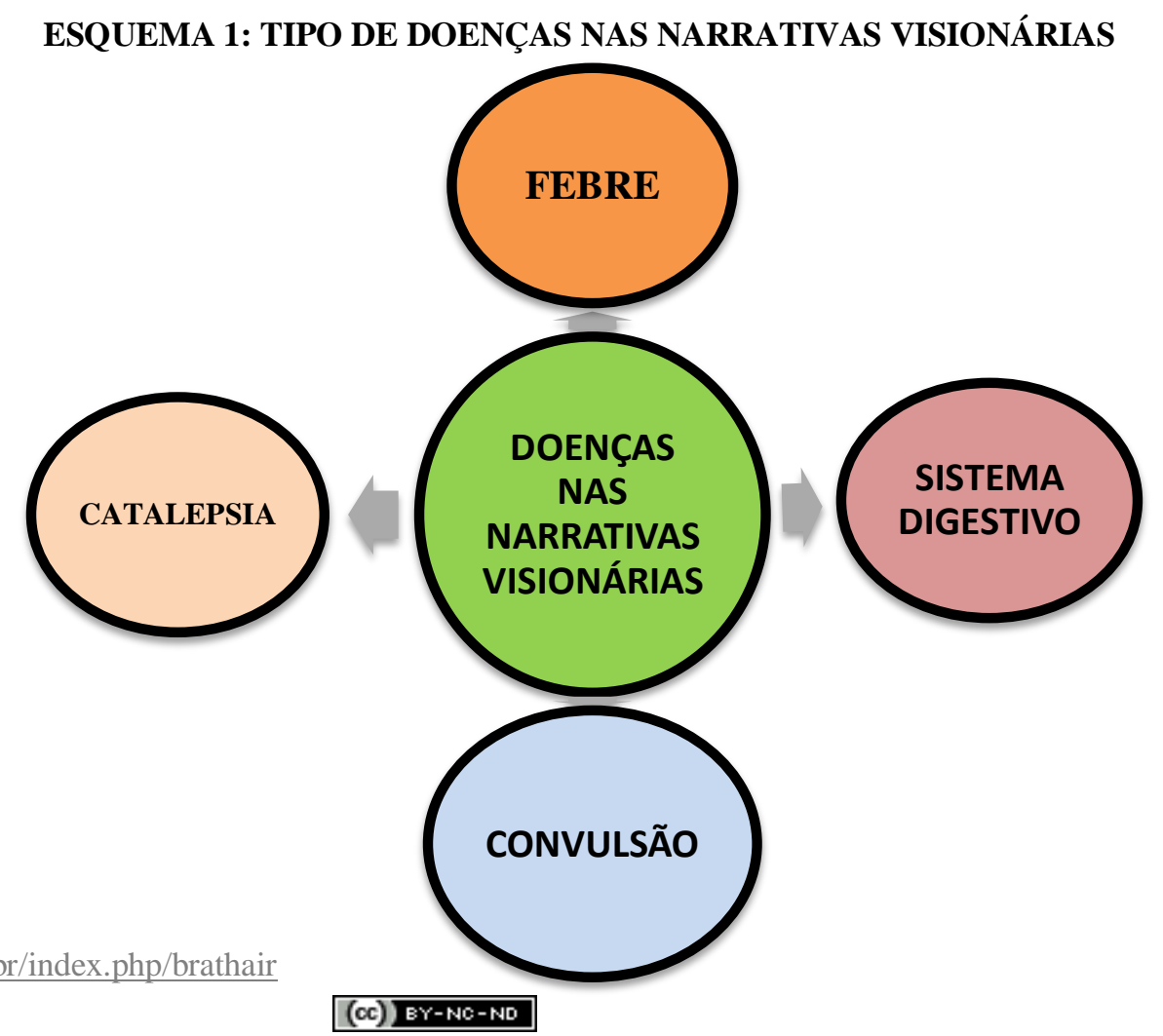


Conforme o esquema 1, a febre, a catalepsia, a paralisia e as doenças do sistema digestivo estão entre as principais enfermidades informadas pelos redatores ao iniciar o relato da visão dos viajantes no Além. Para a enumeração destas, foram feitas seleções de narrativas visionárias do Além medieval que deixam explícita a patologia que afeta o visionário antes da chegada da sua alma à porta da morte.

Evoquemos, então, o corpus de textos visionários na qual a doença é identificada e, conforme já mencionamos, assume uma importância fundamental para as visões dos protagonistas, que quase sempre se originam a partir de um estado patológico. Nesse sentido, exemplificamos, de forma breve, cada uma daquelas doenças no contexto das narrativas, no intuito de revelar as circunstâncias em que estas doenças aparecem na estrutura do relato, isto é, claramente assinaladas, mas, sem a preocupação de descrever a sua progressão e sim uma relação de causa e efeito entre o corpo e a saída temporária da alma.

Comecemos pelo exemplo de uma das narrativas mais antigas de viagens Ao Além Medieval, a Visão de Barontus, obra datada do século VII. Barontus era um nobre senhor que viveu uma trajetória de vida pecaminosa e depois se torna monge. A história se inicia, em 678 ou 679, com ele acometido por uma febre após o ofício divino, isto é o canto da matina, diante dessa situação pede ao seu filho que faça vir um diácono. Este logo o encontra se contorcendo no chão, gesticulando para sua garganta, sendo, portanto, privado de falar o que leva o seu par a interpretar esse frenesi como uma incursão de espíritos malignos. O diácono então faz o sinal da cruz, ora, e borrifa água benta a fim de afastar os maus espíritos. A comunidade então se reúne em torno da cama de Barontus e percebem que ele não se move mais, isto é, se encontra no estado de letargia onde sua alma nesse momento já foi provisoriamente separada do corpo e elevado para o Além. ${ }^{5}$

Diante do exposto, a partir do sintoma da febre sofrida pelo doente visionário Barontus que começa a narrativa da jornada do Outro mundo quando a alma deste é arrebatada para o céu e o inferno. Como se pode perceber neste resumo inicial do relato, não há preocupação em descrever a evolução do ataque de febre que acometeu o corpo do personagem, fica apenas no nível informativo ou sintomático que leva ao processo do início da separação da alma do corpo e da dimensão espaço-material. 
Ainda neste breve resumo, chamamos atenção para a relação da doença com a questão dos espíritos malignos. Observamos que diante das manifestações sintomáticas sofridas por Barontus, tais como, se contorcer pelo chão, apontar para a sua garganta e privação da fala logo é interpretada pelo diácono como uma intervenção do Maligno. Nesta passagem, é um exemplo clássico da crença medieval que responsabiliza este ser por todas as catástrofes do mundo, dentre as quais as próprias doenças que acometiam os homens e as mulheres eram consideradas um artifício diabólico.

O relato se situa na denominada Alta Idade Média, "onde o diabo podia insinuarse no corpo dos homens, "possuí-los" e lhes fazer perder toda a sua vontade própria. É por isso que o ritual de exorcismo, pelo qual a Igreja libera os possuídos adquire grande importância” particularmente nesse período. (BASCHET, 2007, p. 383). Assim, eram recorrentes as instruções teológicas que enumeravam manifestações indicativas de possessão diabólica, para além das já assinaladas na Sagrada Escritura. O próprio visionário Barontus apresenta os sinais de caso de possessão assinaladas na Sagrada Escritura, como a mudez e a gesticulação excessiva. ${ }^{6}$ Porém, "não está claro, entretanto, se este sofrimento fosse por sua doença, pelas faltas morais que o tornavam suscetível a ataques demoníacos, ou pelo caráter intrinsecamente violento da morte". (AMAT, 1985, p.46).

Indo mais adiante na cronologia das narrativas de viagens ao Além, a doença do sistema digestivo é citada na Visão de Wetti, cuja primeira versão é datada em 824 . A narrativa inicia como desenrolar dos sintomas patológicos digestivos sentido por Wetti ao se juntar no refeitório do monastério para jantar com os seus irmãos monges. Este acaba sentindo dores terríveis, nas primeiras horas da noite. Daí em diante não conseguir comer mais, sendo, portanto, acometido por dificuldades digestivas, como a indigestão e náuseas intensas que duram dias até a chegada da sua morte temporária quando tem a sua primeira visão do Além. Assim como no relato mencionado anteriormente, não se observa também na Visão Wettin a preocupação dos redatores em descrever a evolução da doença como em um tratado medicinal, mas sem dúvidas, se assim podemos inferir, em associá-la a causa que vai permitir a morte aparente e o inicio da viagem da alma no pós-morte. ${ }^{7}$

Para ficarmos somente nesses dois exemplos de viagens visionárias ao Além Medieval, do mesmo modo, as outras doenças já citadas, a convulsão e a catalepsia, são 
identificadas nas estruturas desses relatos como o elemento principal que vai ocasionar a morte aparente e o início da viagem da alma do protagonista para o Outro Mundo. ${ }^{8}$

Em relação à doença da catalepsia, Jacqueline Amat explica a associação desta com a viagem ao Além está estritamente ligada às tradições greco-latina, conforme escreve:

\begin{abstract}
A visão se reconecta com a tradição greco-latina dos comas catalépticos, durante os quais a alma de um ser, suspensa entre a vida e a morte, viajava para o Além. Tais experiências eram geralmente citadas como evidência da imortalidade da alma e até mesmo foram tão longe, ao que parece para provoca-la [...]. (AMAT, 1985, p.375)
\end{abstract}

Enfim, o motivo tópico da doença está presente em várias estruturas das narrativas visionárias do Além, mas como já informamos nesse texto, isso não se constitui em uma recorrência presente em todas as narrativas desse gênero. E quando estão presentes, entre as várias versões feitas, os redatores optam por negligenciar o topos da doença nestes relatos.

Neste caso, evocamos um exemplo que faz parte do corpus de narrativas visionárias ao Além, a Visão de Túndalo, cujo texto é de origem latina do ano de 1149. A princípio, o relato apresenta logo no início que o protagonista Túndalo se apresenta em plena saúde quando ele vai fazer uma cobrança de uma dívida em Cork, localizado no sul de Munster, local onde se deu a sua experiência visionária. Tudo começa quando o cavaleiro vai visitar um amigo para reclamar o pagamento de três cavalos. Ele aguarda durante três noites para receber o pagamento, mas não tem retorno e questiona logo o anfitrião, este não teve condições de lhe pagar, deixando-o com raiva. $\mathrm{O}$ devedor o convidou, então, para um jantar. Quando Túndalo se sentou à mesa assim que estendeu a mão para se servir ele não conseguiu levá-la até a boca, esse é o momento em que se inicia a sua viagem para o Além. ${ }^{9}$

É exatamente durante a refeição com o anfitrião, que ele é atingido por um golpe invisível que causa sua morte temporária e êxtase de sua alma. A doença está aqui completamente ausente. Segundo Cavagna, se referindo principalmente as versões francesas dessa viagem imaginária ao Além, "negligencia-se completamente o episódio 
da alimentação e se atribuiu ao protagonista a uma grave doença." ( CAVAGNA, 2004, p. 3)

No entanto, as especificações de cada estado e momento das ações do cavaleiro têm uma função essencial para ratificar a realidade do início da sua experiência no pósmorte. Conforme Yolande Pontfracy: "Todos esses lugares tempo e momentos "de passagem" (cólera restrita a amizade, absorção de alimento) se conjugam para ancorar a realidade da experiência de Túndalo, ao criar este espaço intermediário, peculiar a uma abertura para o Além”. (PONTFARCY, 2013, p. 200-201).

Observamos que ele, ao se sentar à mesa para comer, não conseguiu levar o alimento até a boca, porque foi o momento em que não conseguiu mais se movimentar, entrando em estado de coma, instante que acontece o deslocamento da alma de seu corpo que parte em viagem.

Dessa forma, as variações dos sintomas de Túndalo, antes da separação da alma de seu corpo, são apontadas de várias maneiras em diferentes versões da narrativa. É possível encontrarmos em algumas das suas versões apresentarem que o mesmo estava ou em estado de coma, transe, catalepsia e êxtase como fenômenos que dão início à sua experiência no Além. Tais estados são as principais modalidades apresentadas por diversos autores para justificar a entrada da alma de Túndalo no Além.

Diante do exposto, o fato é que as doenças evocadas nas estruturas das narrativas visionárias do Além Medieval desempenham uma função importante para o início do relato da viagem dos protagonistas-visionários no além-túmulo. Pois é ao curso de um estado patológico que ocorre a morte aparente e consequentemente a visão, características encontrada na maioria dos textos desse gênero literário. 
Embora, nem sempre o começo da jornada dos visionários se realiza em decorrência de uma enfermidade os numerosos corpus partem da doença como o fenômeno que vai dar o processo de separação da alma da dimensão corporal. E da mesma forma é o elemento que o separa da dimensão espacial, isto é, do Aqui embaixo para outra, o Além. Como cita Mattias Cavagna: “A condição do enfermo é o primeiro grau de alienação do mundo que levará precisamente à separação da alma da dimensão corporal e material." (CAVAGNA, 2004, p, 43). É neste sentido que estado patológico do visionário permite que a narrativa evidencie de forma mais clara o momento das vicissitudes que cercam a partida da alma e os sinais da morte aparente.

\section{Referências:}

\section{Fontes Primárias}

Bíblia de Jerusalém. São Paulo: Paulus, 2002.

WAGNER, Albrecht. Visio Tnugdali. Lateinsch und Altdeutsch. Erlangen. Verlag Von Andreas Deichert, 1882;

The Vision of Tnugdalus. Eletronic edition in latin compiled by Beatrix Farber, com base no ms Munchen, Bayerische Staatsbibliotek, codices latini, 22254, (século XII) f. $\{$ MS f. 117vb $\quad[p .2]$; MS. $\{118 \mathrm{ra}\}$ [p.3]. Disponível em: $\leq$ https://celt. ucc.ie/published/L207009.html $\geq$. Acesso em 10 Nov. 2020.

\section{$\underline{\text { Referências Gerais }}$}

AMAT, Jacqueline. Songes et visions. L' au-delá dans le litterature Latina Tardive. Paris: Études Augustiniennes, 1985.

BASCHET, Jérôme. A Civilização Feudal: do ano mil à colonização da América. São Paulo: Ed. Globo, 2006.

. Corps et âmes: une histoire de la personne au Moyen Âge.

Aubier, Flammarion, 2016. 
BASTOS, Mário Jorge da Motta. O poder nos tempos da peste. Niterói: EDUFF, 2009.

Claude Carrozi: Le Voyage de l'âme dans l'au-delà d'après la littérature latine (VeXIIIe siècle). Rome : École Française de Rome, 1994. (Publications de l' École française de Rome, 189). Disponível em: $\leq$ www.persee.fr/doc/efr 00000000_1994_ths 189 1 12 . Acesso em: Acesso: 08 out. 2020.

CAVAGNA, Mattia, La "Visione di Tungdal” e la Scoperta dell'Inferno. In: Studii Celtici, 2004.

Disponível

em:

$\leq$ http://www2.lingue.unibo.it/studi\%20celtici/Articolo_9_\%28Cavagna\%29.pdf. $\quad \geq$. Acesso em: 08 out. 2020.

CAVAGNA, Mattia. La maladie dans les récits visionnaires médiévaux. In: La maladie et la mort au Moyen Âge. Actes du Colloque de Amiens, Press du Centre d' Études Mediévales, Université de Picardie, 2004, p. 36-45.

DELUMEAU, Jean. O que sobrou do Paraíso? São Paulo: Companhia das Letras, 2003.

DINZELBACHER, Peter. La littérature des Révélation au Moyen âge. In: Um document historique. Revue Historique, T. 275, Fasc. 2 (558), Published by: Presses Universitaires de France, p.294. Disponível em: s

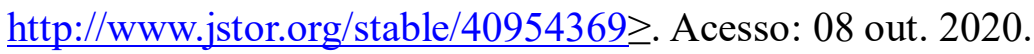

LAWERS, Michel. Morte e Mortos. In: Dicionário Temático do Ocidente Medieval. São Paulo: EDUSC/Imprensa Oficial do Estado, vol. II, 2002, p. 243-261.

LEDDA, Giuseppe. A literatura visionária e a representação do Além. In: Idade Média: bárbaros, cristãos e muçulmanos, v.1. ECO, Umberto (org.). Lisboa: Editor Dom Quixote, 2010.

LE GOFF, Jaques (Org.). As doenças têm história. Lisboa: Terramar, 1985.

LE GOFF, Jacques. Sonho. In: Dicionário Temático do Ocidente Medieval. São Paulo: EDUSC/Imprensa Oficial do Estado, vol. II, 2002, p. 511-529.

LE GOFF, Jacques; Truong, Nicolas. Uma história do corpo na Idade Média. Rio de Janeiro: Civilização Brasileira, 2006. 
NOGUEIRA, Carlos Roberto F. O Diabo no imaginário cristão. 2a . ed. Bauru, SP: EDUSC, 2002.

PONTFARCY, Yolande de. Justice humaine et justice divine dans la Visio Tnugdali et le Tractatus de Purgatorio Sancti Patricii ", Cahiers de recherches médiévales et humanistes [En ligne], 26 | 2013, mis em ligne le 30 décembre 2016, DOI: 10.4000/crm.13406. Disponível em: $\leq$ http://crm.revues.org/13406 $\geq$. Acesso em: 08 out. 2020 .

RICHARDS, Jeffrey. Sexo, desvio e danação: as minorias na Idade Média. Rio de Janeiro: Jorge Zahar Editos, 1993.

ROMANO, Ruggiero (dir.). Religião-Rito. Enciclopédia Einaudi. Lisboa: Imprensa Nacional - Casa da Moeda, 1994.

SCHMITT, Jean-Claude. Os vivos e os mortos no Ocidente Medieval. São Paulo: Companhia das Letras, 1999.

SCHMITT, Jean-Claude. O corpo das imagens: ensaios sobre a cultura visual na Idade Média. Bauru, SP: EDUSC, 2007.

SCHMITT, Jean-Claude. O corpo, os ritos, os sonhos, o tempo: Ensaios de antropologia medieval. Petrópolis: Editora Vozes, 2018.

ZIERER, Adriana Maria de Souza. Paraíso e Inferno na Visión de Don Tungano (Visão de Túndalo): um percurso para a salvação. Revista Notandum. Ano XIX - Nº42. CEMOrOC- Feusp / IJI-Univ. do Porto, 2016, p. 1-19. Disponível em:

$<$ http://www.hottopos.com/notand42/1\%20Adriana\%20Maria\%20de\%20Souza $\%$ 20Zierer.pdf Acesso em: 08 out. 2020.

\section{Notas}

\footnotetext{
${ }^{1}$ Para mais informações sobre a multiplicidade de sentido de visão ou visio e outras modalidades próximas desse termo, consultar: DINZELBACHER, Peter. La littérature des Révélation au Moyen âge. In: Um document historique. Revue Historique, T. 275, Fasc. 2 (558), Published by: Presses Universitaires de France, p.294. Disponível em: 〈http://www.jstor.org/stable/40954369>. Acesso: 08 out. 2020. DELUMEAU, Jean. O que sobrou do Paraíso? São Paulo: Companhia das Letras, 2003, p. 86. ROMANO, Ruggiero (dir.). Religião-Rito. Enciclopédia Einaudi. Lisboa: Imprensa Nacional - Casa da Moeda, 1994, p. 275.

${ }^{2}$ De acordo com os estudos de Claude Carozzi, dentre 36 narrativas visionárias ao Além, 25 mencionam a doença como o principalmente de quase morte do protagonista, embora esta não seja descrita sempre da mesma forma. Para mais informações consultar: Carozzi, Claude. Le Voyage de l'âme dans l'au-delà
} 
d'après la littérature latine (Ve-XIIIe siècle) Rome : École Française de Rome, 1994. 720 p. (Publications de l'École française de Rome, 189), p.568. Disponível em: www.persee.fr/doc/efr_00000000_1994_ths_189_1. Acesso em: 08 out. 2020.

${ }^{3}$ As narrativas de Visões contadas pelo eremita espanhol Valerius de Bierzo, por volta de 675- 680, são uns dos exemplos, onde os personagens apresenta ou durante uma doença (não especificada) tem sua alma elevada temporariamente para o Além. Destaca-se o relato de um monge denominado Máximo que Valerius conta que este adoece,morre, e então depois de várias horas retorna ao seu corpo e relata a sua viagem ao além. Para melhor detalhamento consultar: Carozzi Claude. Le Voyage de l'âme dans l'au-delà d'après la littérature latine (Ve-XIIIe siècle) Rome : École Française de Rome, 1994. (Publications de l'École française de Rome, 189), p.568. Disponível em: www.persee.fr/doc/efr_000000001994 ths 189 1, p. 72- 75. Acesso em: Acesso: 08 out. 2020.

${ }^{4}$ Para mais detalhes sobre esse relato visionário consultar: Carozzi, Claude. Le Voyage de l'âme dans l'au-delà d'après la littérature latine (Ve-XIIIe siècle) Rome : École Française de Rome, 1994, p. 195.

${ }_{5}^{5}$ Para mais informações conferir a Visão de Barontus editada por E. Krusch. Vision Baronti monachi Logorotensis, nos Monumento Germaniae histórica (Scriptores rerum merovingicarum) V. p. 377-394. O resumo deta versão pode ser conferida em Carozzi Claude. Le Voyage de l'âme dans l'au-delà d'après la littérature latine (Ve-XIIIe siècle). Rome: École Française de Rome, 1994. (Publications de l'École française de Rome, 189), p.568. Disponível em: www.persee.fr/doc/efr_0000-0000_1994_ths_189_1, p. 139-180. Acesso em: Acesso: 08 out. 2020.

${ }^{6}$ Para mais informações sobre quais manifestações indicativas de possessões diabólicas são enumeradas pelos teólogos, conferir: NOGUEIRA. Carlos Roberto F. O Diabo no imaginário cristão. 2.ed. Bauru:EDUSC,2002, p. 56-59.

${ }^{7}$ C.f. Claude Carrozi: Le Voyage de l'âme dans l'au-delà d'après la littérature latine (Ve-XIIIe siècle) Rome : École Française de Rome, 1994. (Publications de l' École française de Rome, 189), p.324-346. Disponível em: www.persee.fr/doc/efr_0000-0000 1994 ths 189 1. p. 139-180. Acesso em: Acesso: 08 out. 2020. E ainda desse mesmo autor, utilizou as duas edições da Visão de Wettin a de E. Dimmoler, Munumenta Germanie histórica, PLM,II, e a outra de D.A. Traill,Walahfrid Strabo'visio Wettini (Lateeinishe Sprache und Litteratur des Mittelalalters,2), Berna /Frankfurt,1974.

${ }^{8}$ Claude Carozzi apresenta em sua obra fundamental sobre a viagem das almas, um corpus de narrativas visionárias que identificam estas e outras doenças na estrutura dos relatos. Cf. Claude Carrozi: Le Voyage de l'âme dans l'au-delà d'après la littérature latine (Ve-XIIIe siècle) Rome : École Française de Rome, 1994. (Publications de l' École française de Rome, 189), p.324-346. Disponível em: www.persee.fr/doc/efr_0000-0000_1994 ths 189_1. p. 569. Acesso em: Acesso: 08 out. 2020

${ }^{9}$ Foram consultadas as seguintes obras para essa questão: WAGNER, Albrecht. Visio Tnugdali. Lateinsch und Altdeutsch. Erlangen. Verlag Von Andreas Deichert, 1882; The Vision of Tnugdalus. Eletronic edition in latin compiled by Beatrix Farber, com base no ms Munchen, Bayerische Staatsbibliotek, codices latini, 22254, (século XII) f. \{ MS f. 117vb\} [p.2]; MS. 118ra\} [p.3]. Disponível em: <https://celt.ucc.ie/published/L207009.html >. Acesso em Acesso: 08 out. 2020; Carozzi Claude. Le Voyage de l'âme dans l'au-delà d'après la littérature latine (Ve-XIIIe siècle) Rome : École Française de Rome, 1994,p. 558; PONTFARCY, Yolande de. Justice humaine et justice divine dans la Visio Tnugdali et le Tractatus de Purgatorio Sancti Patricii », Cahiers de recherches médiévales et humanistes [En ligne], 26 | 2013, mis em ligne le 30 décembre 2016,DOI :10.4000/crm.13406. Disponível em: <http://crm.revues.org/13406>. ZIERER, Adriana Maria de Souza. Paraíso e Inferno na Visión de Don Tungano (Visão de Túndalo): um percurso para a salvação. Revista Notandum. Ano XIX - Nơ42. CEMOrOC- Feusp / IJI-Univ. do Porto, 2016, p. 1-19. 